\title{
Differential distribution of VGF-derived peptides in the adrenal medulla and evidence for their selective modulation
}

\author{
Filomena D'Amato ${ }^{1}$, Barbara Noli ${ }^{1}$, Carla Brancia ${ }^{1}$, Cristina Cocco ${ }^{1}$, Giovanna Flore ${ }^{2}$, Maria Collu ${ }^{2}$, \\ Paola Nicolussi ${ }^{3}$ and Gian-Luca Ferri ${ }^{1}$ \\ ${ }^{1}$ NEF-Laboratory, Department of Cytomorphology, ${ }^{2}$ Department of Neuroscience, University of Cagliari, I-09042 Monserrato (Cagliari), Italy \\ ${ }^{3}$ Istituto Zooprofilattico Sperimentale, I-07100 Sassari (SS), Italy \\ (Correspondence should be addressed to G-L Ferri; Email: ferri@unica.it)
}

\begin{abstract}
While vgf gene knockout mice are hyperactive and hypermetabolic, surprisingly the TLQP-21 brain VGF peptide increased energy consumption, suggesting that opposing regulatory effects could be exerted by peptides alternatively cleaved from the VGF precursor. Using antisera to the VGF precursor C-terminus and three cleavage products, we revealed a distinct differential distribution in adrenal, certain peptides $\left(\mathrm{VGF}_{422-430}\right.$ : PGH peptides) being found throughout bovine and swine medulla, while C-terminus and TLQP peptides were confined to adrenaline cells in the above species and in rat and C-terminally shortened forms ( $\mathrm{VGF}_{604-612}$ : HVLL peptides) to nor-adrenaline cells. Random abattoir samples of bovine and swine adrenal contained $520 \pm 40$ and $450 \pm 60 \mathrm{pmol} / \mathrm{g}$ (mean \pm s.E.M. respectively) of C-terminus peptides and similar or lower amounts of others. Upon gel chromatography, bona fide VGF precursor, $\sim 7.5$ and
\end{abstract}

$\sim 3.5 \mathrm{kDa}$ forms were revealed by C-terminus assays, HVLL peptides being limited to small fragments. TLQP peptides included $\sim 7.5 \mathrm{kDa}$ form and peaks accounting for TLQP-21 and predicted TLQP-30 and TLQP-42. Low molecular weight (MW) PGH peptides were revealed, together with a high MW form possibly encompassing the VGF precursor N-terminus. In acutely stressed swine, a striking increase was seen for C-terminus and TLQP peptides, with no significant differences for PGH peptides. A similar response was found in rat TLQP peptides showing a major increase upon an acute swimming stress and $30 \mathrm{~min}$ thereafter. A differential processing of the VGF precursor encompassing many areas of its primary sequence and selective modulations of its derived peptides occur in adrenal medullary cells, possibly relevant to adaptive homeostatic responses.

Journal of Endocrinology (2008) 197, 359-369

\section{Introduction}

The $v g f$ (non-acronymic) gene was discovered because of its distinct, selective up-regulation by nerve growth factor in the PC12 rat pheochromocytoma cell line (Levi et al. 1985) and proved to be selectively expressed in a range of neuroendocrine cell types (Ferri et al. 1992, Salton et al. 2000, Levi et al. 2004). The primary gene product, VGF protein or VGF precursor, is composed of 617 or 615 amino acids (in rat/ mouse and man respectively, $>85 \%$ identity, $\sim 65 \mathrm{kDa}$ calculated molecular weight $(\mathrm{MW})$ ) and migrates as $\sim 90 \mathrm{kDa}$ MW band in western blot (Salton et al. 2000). The primary sequence of VGF shows at least ten short stretches of basic amino acid residues, highly conserved across species, which could be target sites for endoprotease activity, with cleavage to smaller VGF peptides (Salton et al. 2000). The 30 amino acid 'peptide V' was isolated from bovine posterior pituitary (Liu et al. 1994), and, upon sequencing of the relevant region of human (Canu et al. 1997, Salton et al. 2000) and bovine VGF (accession No. XP_875466.2), proved to correspond to the 30 amino acid portion of VGF comprised between the $\operatorname{Arg}_{584}-\operatorname{Arg}_{585}$ (numbering according to human VGF) putative cleavage site and the C-terminus. In rat brain, lower MW peptides $(10,18$ and $20 \mathrm{kDa})$ were detected by an antiserum against the C-terminal VGF nonapeptide (Trani et al. 1995, 2002). Processing at the rat VGF $\operatorname{Arg}_{553}-\operatorname{Pro}_{554}-$ Arg $_{555}$ cleavage site resulted in further VGF peptides isolated from rat brain and called TLQP peptides from their $\mathrm{N}$-terminal sequence (Trani et al. 2002). When VGF peptide release in response to secretory stimuli was studied in vitro, low MW C-terminal peptides were released preferentially, as opposed to high MW forms (Possenti et al. 1989, 1999, Trani et al. 1995).

VGF-deficient (knockout) mice are hyperactive and hypermetabolic, with altered energy homeostasis, decreased body weight and especially body fat, and a deranged hypothalamic response to feeding (Hahm et al. 1999, 2002). Nonetheless, intracerebroventricular injection of the VGF precursor-derived TLQP-21 brain peptide increased resting energy expenditure, body temperature and circulating adrenaline levels (Bartolomucci et al. 2006), indicative of a stimulatory action on the autonomic nervous system and 
adrenal medulla. In addition, when TLQP-21-treated mice were fed a high-fat diet, their expected increase in body weight and white adipose tissue was prevented (Bartolomucci et al. 2006). On the whole, vgf gene inactivation and the administration of its derived TLQP-21 peptide product showed surprising similarities, suggesting that different VGF peptides, out of the many which are or can be produced by differential cleavage of VGF, may well have opposing activities.

In the rat adrenal, immunoreactive medullary cells were seen using antisera to VGF-fusion proteins encompassing extended portions of the VGF precursor (Ferri et al. 1992), while VGF mRNA was low compared with pituitary and hypothalamus (Salton et al. 1991, Ferri et al. 1992). Upon reserpine treatment, VGF mRNA showed a striking increase lasting for days $1-5$ (earliest and latest time points studied), probably mediated by sympathetic stimulation via the splanchnic nerve (Laslop et al. 1994). In western blot of rat adrenal extracts, a rat VGF C-terminus ( $\left.\mathrm{VGF}_{609-617}\right)$ antiserum revealed intact VGF, but little low MW forms (Trani et al. 1995). In humans, an immunocytochemical study using human VGF C-terminus and rat $\mathrm{VGF}_{422-430}$ antisera showed labelled medullary cells from the tenth week of gestation, as well as in adult adrenal and its medullary tumours (Rindi et al. 2007).

In view of the crucial involvement of the adrenal in the adaptive responses and in the regulation of energy homeostasis, we aimed to study the VGF peptides it contained. In order to specifically address VGF processing and its derived peptides, we used antisera to the $\mathrm{C}$-terminus of rat and human VGF, as well as to three amino acid stretches adjacent to demonstrated or putative VGF precursor cleavage sites.

\section{Materials and Methods}

\section{Tissue samples and processing}

Adrenal glands were collected at random from a local abattoir from bovine (male and female, 7-11 months, $n=14$ ) and swine (female and castrated male, 7-9 months, $n=22$ ). Samples of liver and spleen were taken as control tissues. All animals were from local farms (travel time to abattoir 0.5 to $\sim 3 \mathrm{~h}$ ) and routinely received a limited amount of food on the day preceding slaughter to facilitate butchery procedures. In view of the stress involved in transportation and animal regrouping, we also identified a group of swine $(n=102$, 65-7 months, raised at one and the same farm by crossing Pietrain halothane free sires with Landrace sows), which was to be stabulated at a local abattoir site for over 3 days after transportation. Animals were led to a clean butchery line early on the following Monday, and adrenals were taken from animals butchered first $(n=6)$ and last $(n=6)$, so that animals stayed in line for 1-5 and 25-30 min respectively, before being stunned with electricity and ejugulated. In connection with butchery procedures, tissues were made available between 40 and 55 min after ejugulation in all cases.
Individual rats from a first random sacrifice group were taken from their cages (two to four rats/cage) in sequence and were killed by decapitation $(n=10$, Sprague-Dawley rats of either sex, 250-300 g body weight). The effect of stress was further studied in rats (250-350 g body weight of either sex: female rats underwent vaginal smears and were used when in dioestrus). These were either rapidly moved to a killing box containing diethyl ether vapour $(n=10$, minimum stress group: rats from each two to three animals per cage were moved to the killing box at once within 5-10 s), similarly killed after an acute swimming stress $\left(5 \mathrm{~min}\right.$ duration, $25^{\circ} \mathrm{C}$ water, $n=12$, acute stress group) or after the same stress followed by a $30 \mathrm{~min}$ recovery period $(n=6$, 'stress + recovery' group). Experimental protocols were approved by the Ethical Committee at the University of Cagliari and were performed in accordance with the care and use of animals approved by the American Physiological Society and EEC Council Directive of 24 November 1986 (86/609).

For immunocytochemistry, thin slices of bovine/swine adrenal $(2-3 \mathrm{~mm}$ ) or rat adrenals (cut into two) were immersion-fixed in paraformaldehyde $\left(40 \mathrm{~g} / 1\right.$ in $\mathrm{PO}_{4}$ buffer, $02 \mathrm{~mol} / \mathrm{l}(\mathrm{pH}=72) ; 3 \mathrm{~h}$ at $\left.0-4{ }^{\circ} \mathrm{C}\right)$, washed with PBS containing $70 \mathrm{~g} / 1$ sucrose and $0 \cdot 2 \mathrm{~g} / 1 \mathrm{NaN}_{3}$, oriented in aluminium foil moulds with cryoembedding media and snap frozen (Cocco et al. 2003), hence stored in a liquid nitrogen tank (vapour phase). Cryosections $(5-7 \mu \mathrm{m})$ were obtained using a Microm HM-560 cold-blade cryomicrotome, collected on slides pre-treated with poly-L-lysine and stored as above.

For peptide extraction, adrenal samples were weighed, coarsely minced with a scalpel, dropped into pre-heated polypropylene tubes containing distilled water $(\sim 10 \mathrm{ml} / \mathrm{g}$ tissue), kept in a vigorously boiling water bath for an additional 10-15 min, hence homogenized using an Ultra Turrax (3-5 min; Ika-Werke, Staufen, Germany) and centrifuged (10-15 min, $3000 \mathrm{~g}$ ). Rat adrenals, and some parallel samples from bovine and swine, were homogenized fresh in the presence of protease inhibitor cocktail (Sigma), briefly spun, hence supernatants were boiled as above. Extracts were kept frozen until used $\left(-20{ }^{\circ} \mathrm{C}\right.$ or lower).

\section{VGF peptide antibodies}

VGF antisera were raised against peptide sequences at the VGF C-terminus or adjacent to three dibasic cleavage sites (Fig. 1, while all antisera are listed in Table 1). At the C-terminal end of rat and mouse VGF, a $\mathrm{His}_{615^{-}} \mathrm{Arg}_{616^{-}}$ $\mathrm{Pro}_{617}$ sequence is found, as opposed to $\mathrm{Arg}_{613}-\mathrm{Arg}_{614}-\mathrm{Pro}_{615}$ in man (Salton et al. 2000), hence antisera were raised against rat $\mathrm{VGF}_{609-617}$ (Ferri et al. 1995) and human $\mathrm{VGF}_{607-615}$ (Brancia et al. 2005) conjugated via their N-terminal tyrosine. Since the above $\operatorname{Arg}_{613}-\operatorname{Arg}_{614}$ sequence might also function as a cleavage site, the preceding decapeptide (human $\mathrm{VGF}_{603-612)}$ was synthesized and conjugated at its N-terminus (Biomol, Exeter, UK). TLQP peptides were isolated from rat brain and proved to be cleaved from VGF at 


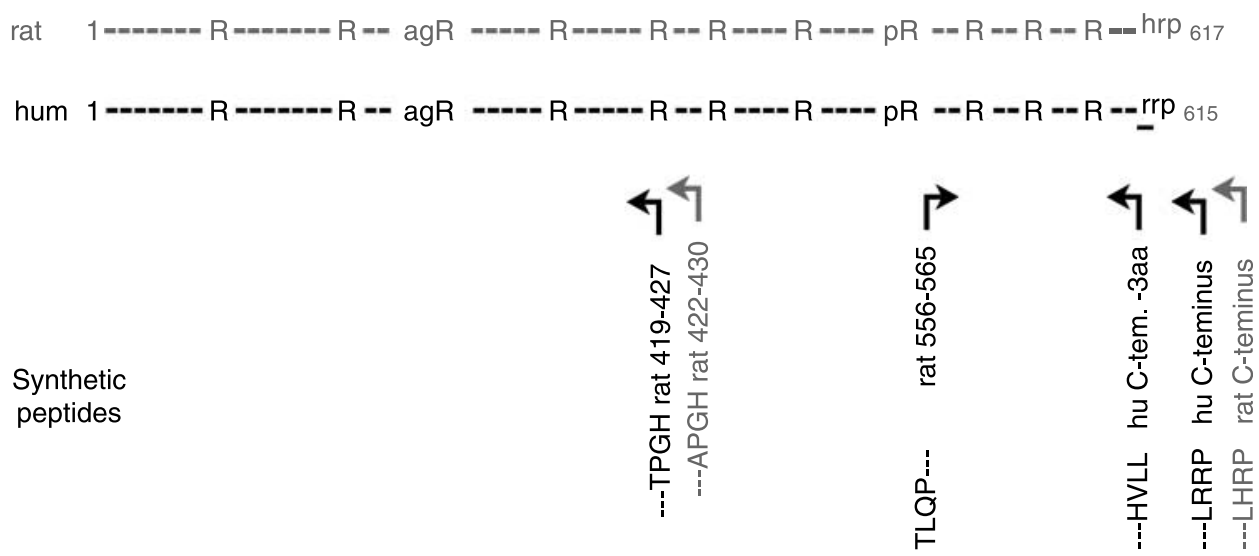

Fusion protein

gst_rat TLQP-21

Figure 1 VGF and antisera. Peptides and fusion protein used to raise antisera and their short names (see Table 1) are plotted onto a schematic outline of the VGF precursor. Arrowheads are directed according to expected antiserum reactivity; ' $\mathrm{R}$ ' demonstrated or putative processing sites (two or more Arg/Lys basic residues); 'pR', Arg-Pro-Arg processing site (Trani et al. 2002); 'agR', putative processingamidation site, Ala-Gly-Arg-Arg; last 3 C-terminal amino acids are indicated in single-letter notation ('Arg' residue, differing in human versus rat/mouse, is underlined); 'hu', human; 'hu C-terminus - 3aa', human $\mathrm{VGF}_{603-612}$, identical to rat $\mathrm{VGF}_{605-614}$.

the rat $\mathrm{VGF}_{553-555}\left(\operatorname{Arg}_{553}-\operatorname{Pro}_{554}-\operatorname{Arg}_{555}\right)$ processing site (Trani et al. 2002), at least their N-terminal five amino acids (TLQPP or Thr-Leu-Gln-Pro-Pro) being identical in human and rat VGF. The rat $\mathrm{VGF}_{556-565}$ peptide was synthesized and conjugated at its $\mathrm{C}$-terminus to expose the $\mathrm{N}$-terminal region during immunization (Brancia et al. 2005). A fusion protein composed of a 21 amino acid peptide (rat $\mathrm{VGF}_{556-576}$ or rat TLQP-21) plus glutathione S-transferase (GST, from Schistosoma japonicum species) linked via the peptide's N-terminal ' $\mathrm{T}$ ' (threonine) was obtained using the pGEX-4T-3 plasmid vector (Amersham Pharmacia), and its derived antiserum was used in immunohistochemistry (Brancia et al. 2005). The rat $\mathrm{VGF}_{422-430}$ peptide, as well as the human $\mathrm{VGF}_{419-427}$ peptide (which shows a single amino acid difference compared with bovine, as from accession no. XP_875466.2, an Arg residue being found at position -7 from $\mathrm{C}$-terminus in bovine, as opposed to a Gln residue in human), was synthesized (Biomol) and conjugated via an N-terminal tyrosine (Ferri et al. 1995).

\section{Immunohistochemistry}

Slides were treated with Triton X-100 (Merck; $1 \mathrm{~g} / \mathrm{l}$ in $\mathrm{H}_{2} \mathrm{O}$, $1 \mathrm{~h})$, washed with PBS (10 mmol/1 $\mathrm{PO}_{4}, 150 \mathrm{mmol} / \mathrm{l} \mathrm{NaCl}$ ( $\mathrm{pH} 7 \cdot 2-7 \cdot 4)$ ) and incubated overnight (at room temperature) with primary antiserum/a diluted in PBS containing $30 \mathrm{ml} / 1$

Table 1 Primary antisera used

\begin{tabular}{|c|c|c|c|c|}
\hline & Short name & Use & Species & Reference/producer \\
\hline Human VGF $607-615$ & VGF C-term. (hum) & $\mathrm{I}, \mathrm{E}$ & Rabbit & Brancia et al. (2005) \\
\hline Human VGF $603-612$ & HVLL peptides & I.E & Rabbit & This paper \\
\hline Rat $V_{G F} F_{56-565}$ & TLQP peptides & I.E & G-pig & Brancia et al. (2005) \\
\hline GST-Rat VGF $_{556-576}$ & GST-TLQP-21 & 1 & G-pig & Brancia et al. (2005) and Bartolomucci et al. (2006) \\
\hline Human $V_{G F} 419-427$ & PGH peptides (hum) & $\mathrm{E}$ & Rabbit & This paper \\
\hline Dopamine $\beta$-hydroxylase & $\mathrm{DBH}$ & i & Mouse & Chemicon \\
\hline Phenylethanolamine- $N$-methyl transferase & PNMT & I & Rabbit & Biomol \\
\hline Phenylethanolamine- $N$-methyl transferase & PNMT & I & Sheep & Chemicon \\
\hline
\end{tabular}

GST, Glutathione S-Tranferase; G-pig, guinea pig; use: I, immunohistochemistry; E, ELISA; Biomol, Exeter, UK; Chemicon, Temecula, CA. 
normal serum of the second antibody donor species (donkey), $30 \mathrm{ml} / 1$ normal serum of the species being immunostained (bovine, swine or rat respectively) and $0 \cdot 2 \mathrm{~g} / 1 \mathrm{NaN}_{3}$. Secondary incubations (60 min, room temperature) were carried out with affinity purified donkey antibodies to the relevant species' IgG, conjugated with cyanine 3 (Cy3), cyanine 2 (Cy2) or AMCA (Jackson Immunoresearch, West Grove, PA, USA). For double and triple immunostaining, antisera to VGF peptide/s and/or catecholamine synthesizing enzyme/s (Table 1), each raised in a different species, were mixed followed by the relevant mixture of secondary labelled antibodies. Slides were coverslipped with PBS-glycerol ( 50/ $50 \%)$ and were observed and photographed using BX41 and BX51 fluorescence microscopes (Olympus, Milan, Italy) equipped with Fuji S2 and S3 Pro digital cameras (Fujifilm, Milan, Italy). Immunocytochemical controls included substitution of each antiserum/antibody, in turn, with PBS, as well as the use of single primary antiserum with inappropriate secondary antibodies. For absorption controls, each VGF antiserum was pre-incubated overnight with its own antigen in a range of concentrations $\left(0 \cdot 03-100 \mathrm{~mol} / 1\right.$, at $\left.0-4{ }^{\circ} \mathrm{C}\right)$, hence was used for the primary incubation. The highest $(\sim 2-5)$ concentrations of homologous antigen resulted in virtually complete prevention of labelling with each of the VGF antisera used.

\section{ELISA}

Assays were set up with the six antisera raised against synthetic VGF peptides ( Tables 1 and 2). Multiwell plates (Nunc, Milan, Italy) were coated with the corresponding unconjugated synthetic peptide $(5-50 \mathrm{nmol} / 1$, in carbonatebicarbonate buffer $(\mathrm{pH} 96) ; 4 \mathrm{~h}$ at $37^{\circ} \mathrm{C}$ or $16 \mathrm{~h}$ at $\left.0-4{ }^{\circ} \mathrm{C}\right)$, hence were treated with normal serum from the secondary antibody donor species (PBS-donkey, $90 \mathrm{ml} / \mathrm{l}$ ). Primary incubations were carried out in duplicate, including relevant standards $(0 \cdot 005-500 \mathrm{nmol} / \mathrm{l})$ or serially diluted samples $(100 \mu \mathrm{l} /$ well incubation volume, in PBS-donkey, $4 \mathrm{~h}$ at room temperature under constant agitation). After the relevant incubations ( $1 \mathrm{~h}$ each) with secondary antibody (Jackson) and streptavidin-peroxidase conjugate (Biospa, Milan, Italy), wells were incubated with tetramethylbenzidine substrate $(100 \mu \mathrm{l} /$ well: Sigma or Kem-En-Tec Diagnostics, Taastrup, Denmark), hence the reaction was stopped with $\mathrm{HCl}(1 \mathrm{~mol} / \mathrm{l}, 100 \mu \mathrm{l} /$ well $)$ and optical density was measured at $450 \mathrm{~nm}$ using a multilabel plate reader (Chameleon: Hidex, Turku, Finland). PBS-Tween (05 ml/1 Tween 20) was used for washing throughout. For all assays, when standard peptide was added to tissues before extraction, $>75 \%$ recovery was shown. When parallel boiling-water and fresh-homogenized extracts or bovine/swine samples extracted after a different post-mortem delay ( $40-55 \mathrm{~min})$ were compared, results were comparable (within $80-120 \%$ of each other). Swine and bovine liver and spleen, extracted as negative control tissues, showed undetectable VGF peptide levels. Various synthetic peptides were used for assay characterization (Table 2).
Some experiments were carried out with swine and bovine plasma/serum as the unknown samples. Unfortunately, a high degree of interference was revealed by plasma/serum proteins, so that further developments will be required before circulating VGF peptides and their release can effectively be addressed. Statistical analysis was carried out by one-way ANOVA, followed by post hoc multiple comparison tests or $t$-test (StatistiXL software: www.statistXL.com).

\section{Chromatography}

Extracts $(\sim 2 \mathrm{ml})$ were loaded onto a Sephadex G-50s column $\left(2 \mathrm{~cm}^{2} \times 1 \mathrm{~m}\right.$; Sigma), equilibrated with $50 \mathrm{mM}$ ammonium bicarbonate and eluted with the same buffer. A MW marker kit (MWGF70: Sigma) was used for column calibration. Collected fractions $(3 \mathrm{ml})$ were reduced in volume using a Vacufuge Concentrator (Eppendorf, Milan, Italy). Recovery after chromatography ranged between 80 and $120 \%$ for all peptides tested.

\section{Results}

Adrenal medullary endocrine cells were labelled for VGF peptides in various numbers and intensities in the species tested, with no staining of cortical cells. Occasional immunoreactive nerve fibres were seen, but will not be addressed further here in view of their small numbers. Of the various VGF antisera used, those against human and rat C-terminus proved highly species selective and were reserved to bovine/swine and rat tissues respectively, while HVLL and TLQP peptide antisera were used across species. The rat PGH antiserum worked well in immunohistochemistry in the three species tested here and in humans (Rindi et al. 2007), hence was used throughout, except for ELISA of bovine and swine tissue extracts for which the human PGH antiserum was employed.

PGH immunoreactivity was abundant in the whole adrenal medulla of bovine and swine (Fig. 2A), with a lower number of scattered cells in rat (not shown). Conversely, VGF C-terminus (Figs 2B and $\mathrm{F}$ and $3 \mathrm{~A}$ ) and TLQP peptides (Figs 2C, E and 3B), as well as C-terminally shortened forms (HVLL peptides; Figs 2D and 3E) were found in restricted areas in all three species studied. In both swine and rat, the above overall distribution of VGF peptides was consistently observed across 'minimum stress' and stressed animals.

In all three species studied, TLQP-immunoreactive cells were most abundant, the TLQP peptide (Fig. 2C) and GSTTLQP-21 antisera (Fig. 2E) showing comparable cell populations and regional distributions. VGF C-terminus immunoreactivity was confined to a subfraction of TLQPimmunoreactive cells, staining intensity for either peptide being highly varied on a single-cell basis (Fig. 2F (C-terminus) versus E (TLQP)). Conversely, HVLL peptides (Fig. 2D) showed a virtually complementary distribution compared with either TLQP (Fig. 2C) or VGF C-terminus in 
Table 2 Elisa characterization

\begin{tabular}{|c|c|c|c|}
\hline & Peptide & $\mathbf{I C}_{\mathbf{5 0}}(\mathrm{pmol})^{\mathrm{a}}$ & $\%$ Cross-reactivity \\
\hline \multicolumn{4}{|l|}{ Assay } \\
\hline \multirow[t]{3}{*}{ VGF C-term. (hum) } & hum $V_{G F} F_{607-615}$ & $0 \cdot 5$ & 100 \\
\hline & rat $V_{G F} F_{609-617}$ & 59 & $0 \cdot 8$ \\
\hline & hum $V_{G F} F_{603-612}(H V L L)$ & 132 & $0 \cdot 4$ \\
\hline \multirow[t]{3}{*}{ VGF C-term. (rat) } & rat $\mathrm{VGF}_{609-617}$ & $0 \cdot 02$ & 100 \\
\hline & hum $V_{G F} 607-615$ & $>200$ & $<0 \cdot 01$ \\
\hline & hum VGF $_{603-612}(\mathrm{HVLL})$ & $>200$ & $<0 \cdot 01$ \\
\hline \multirow[t]{3}{*}{ HVLL peptides } & hum VGF $_{603-612}$ (HVLL) & $0 \cdot 3$ & 100 \\
\hline & hum $\mathrm{VGF}_{607-615}$ & 28 & $1 \cdot 0$ \\
\hline & rat $\mathrm{VGF}_{609-617}$ & $8 \cdot 7$ & $3 \cdot 4$ \\
\hline \multirow[t]{3}{*}{ TLQP peptides } & rat $\mathrm{VGF}_{556-564}$ & $1 \cdot 1$ & 100 \\
\hline & rat VGF $_{556-576}($ TLQP-21) & $0 \cdot 6$ & 183 \\
\hline & rat VGF $_{556-567}($ TLQP-11) & $0 \cdot 9$ & 122 \\
\hline \multirow[t]{4}{*}{ PGH peptides (hum) } & hum $\mathrm{VGF}_{419-427}(\mathrm{TPGH})$ & $0 \cdot 5$ & 100 \\
\hline & hum VGF $V_{419-428}(T P G H-R)^{b}$ & 50 & 1 \\
\hline & rat $\mathrm{VGF}_{422-430}(\mathrm{APGH})$ & $2 \cdot 5$ & 20 \\
\hline & rat $\mathrm{VGF}_{422-431}(\mathrm{APGH}-\mathrm{R})^{\mathrm{b}}$ & $>1000$ & $<0 \cdot 05$ \\
\hline \multirow[t]{4}{*}{ PGH peptides (rat) } & rat $\mathrm{VGF}_{422-430}(\mathrm{APGH})$ & $0 \cdot 3$ & 100 \\
\hline & rat $\mathrm{VGF}_{422-431}(\mathrm{APGH}-\mathrm{R})^{\mathrm{b}}$ & $>2000$ & $<0 \cdot 015$ \\
\hline & hum $\mathrm{VGF}_{419-427}(\mathrm{TPGH})$ & $8 \cdot 5$ & $3 \cdot 5$ \\
\hline & hum $V_{G F} F_{19-428}(T P G H-R)^{b}$ & $>2000$ & $<0 \cdot 015$ \\
\hline
\end{tabular}

${ }^{a}$ pmol per assay well, $100 \mu \mathrm{l}$ incubation volume.

${ }^{b}$ For PGH peptide assays, cross-reaction with VGF was addressed using peptides with an additional Arg residue at their C-terminus.

either bovine or swine. In rat too, HVLL-immunoreactive cells showed no co-localization with TLQP peptides, in spite of their low numbers (all groups).

When adrenaline cells were identified on the basis of their content of the adrenaline synthesizing enzyme phenylethanolamine-N-methyl transferase (PNMT; Fig. 3C), they also labelled with the TLQP peptide (Fig. 3B) or GST-TLQP-21 and VGF C-terminus antisera (Fig. 3A). Conversely, in all three species studied, HVLL immunoreactivity (Fig. 3E) was virtually confined to medullary cells reactive for dopamine $\beta$-hydroxylase (DBH) but not for PNMT (Fig. 3D (DBH) versus $\mathrm{F}(\mathrm{PNMT})$ ), hence identified as nor-adrenaline cells. The picture outlined above was delineated using random abattoir samples of bovine and swine adrenal and random killed rats. When minimum stress and acutely stressed swine and rats were compared respectively, a consistent VGF peptide distribution was revealed in either species' adrenals, with somewhat higher immunostaining intensity for TLQP and C-terminus VGF peptides in stressed animal groups.

In ELISA assays, VGF C-terminus and PGH peptides were especially abundant in bovine and swine, while TLQP peptides were well represented in all three species tested (Table 3). Only small amounts of measurable HVLL-like peptides were found, with below detection levels in several samples (Table 3). It ought to be pointed out here that standard samples of bovine and swine adrenals were taken at random from a local abattoir, hence largely under acute stress conditions (see also below). In spite of marked interindividual variability, especially for TLQP peptides, the latter and C-terminus VGF peptides showed a tendency to increase in our random sacrifice rats, too, compared with the minimum stress group (Table 3, columns 3 and 4).

Upon gel chromatography, the VGF C-terminus antiserum (Fig 4A) revealed a major peak close to the void volume, compatible with the expected migration of the VGF precursor, as well as lower MW forms of $\sim 7.5$ and $3.5 \mathrm{kDa}$. These were similar to peptides previously identified in rat brain and named VGF10, for the $\sim 7 \cdot 5 \mathrm{kDa}$ form (Trani et al. 1995, 2002), or from bovine pituitary and named peptide $\mathrm{V}$, for the $\sim 3.5 \mathrm{kDa}$ one (Liu et al. 1994). A high MW peak also compatible with VGF was found with the TLQP and HVLL peptide assays (Fig. 4B and D; see also below), at apparent concentrations in keeping with the minor cross-reaction with VGF, for the TLQP peptide antiserum (Brancia et al. 2005), and with the human VGF C-terminal nonapeptide, for the HVLL peptide assay (Table 2). Several distinct forms were revealed for TLQP peptides (Fig. 5B), including a major peak of $\sim 7.5 \mathrm{kDa}$ at least partly coincident with the one shown for VGF C-terminus (Fig. 5A), and compatible with a peptide running all the way to VGF C-terminus $(\sim 7 \cdot 4 \mathrm{kDa}$ in rat (Trani et al. 2002); 7.5 kDa, as calculated from human VGF (Salton et al. 2000)). The overlapping peaks spanning $2 \cdot 5-$ $5 \mathrm{kDa}$ elution positions (Fig. 4B) could account for TLQP-21 $(\sim 2.4 \mathrm{kDa}$ in rat (Bartolomucci et al. 2006) and $\sim 2.5 \mathrm{kDa}$ as calculated for human VGF (Salton et al. 2000)), as well as for the predicted peptides TLQP-30 and/or TLQP-42 that would result from cleavage at $\mathrm{VGF}_{584-585}$ or $\mathrm{VGF}_{595-596}$ Arg-Arg sites (numbering relevant to human VGF calculated MW $\sim 3.5$ and $\sim 48 \mathrm{kDa}$ respectively). The rat $\mathrm{PGH}$ antiserum showed minimal reactivity with rat and human C-terminally 

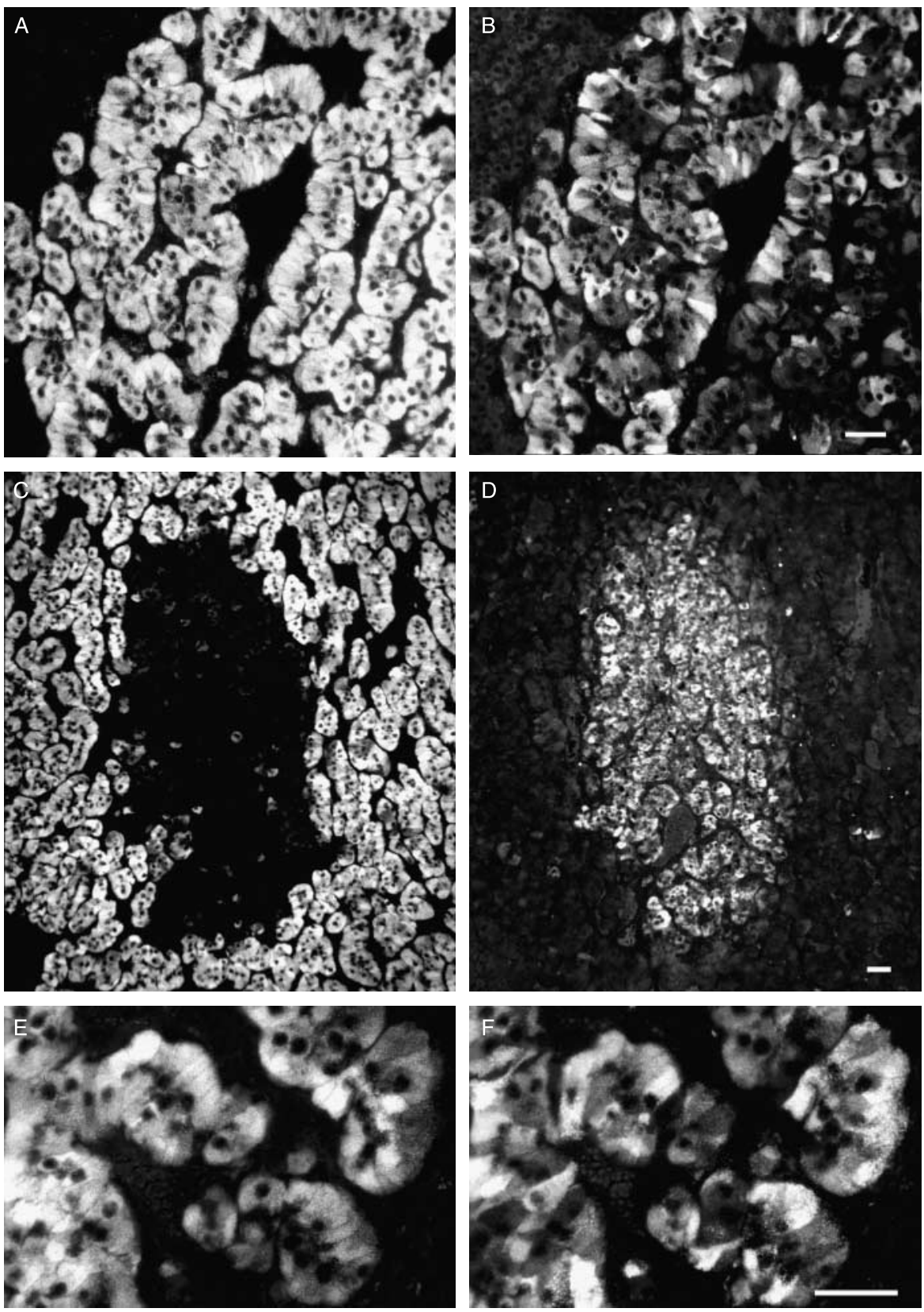

Figure 2 VGF peptide immunolocalization. $\mathrm{PGH}$ peptides were revealed throughout the $(\mathrm{A})$ adrenal medulla, while (B and F) VGF C-terminus, (D) HVLL peptide and (C and E) TLQP peptide immunoreactivity showed a restricted distribution. In all species, VGF C-terminus peptides were confined to a subfraction of TLQP-immunoreactive cells ((F) VGF C-terminus versus (E) GST-TLQP21), while TLQP peptide and GST-TLQP-21 antisera showed a similar localization (C and E respectively) with varied labelling intensity. Conversely, C-terminally shortened (D) HVLL peptides and (C) TLQP peptides were virtually complementary in distribution in all species. Swine adrenal, double immunofluorescence (A-B, C-D, E-F); scale bars, $50 \mathrm{~m}$.

extended peptides (APGH-R/TPGH-R: <0015\% crossreactivity, Table 2), hence chromatography fractions were assessed with such antiserum in order to minimize detection of VGF. While no reactivity was revealed at the elution position of bona fide VGF precursor, a reproducible peak was found several fractions later, at $\sim 45 \mathrm{kDa}$ elution position (Fig. 4C), compatible with a PGH peptide encompassing the VGF N-terminus or nearby. Small MW peptides were also 

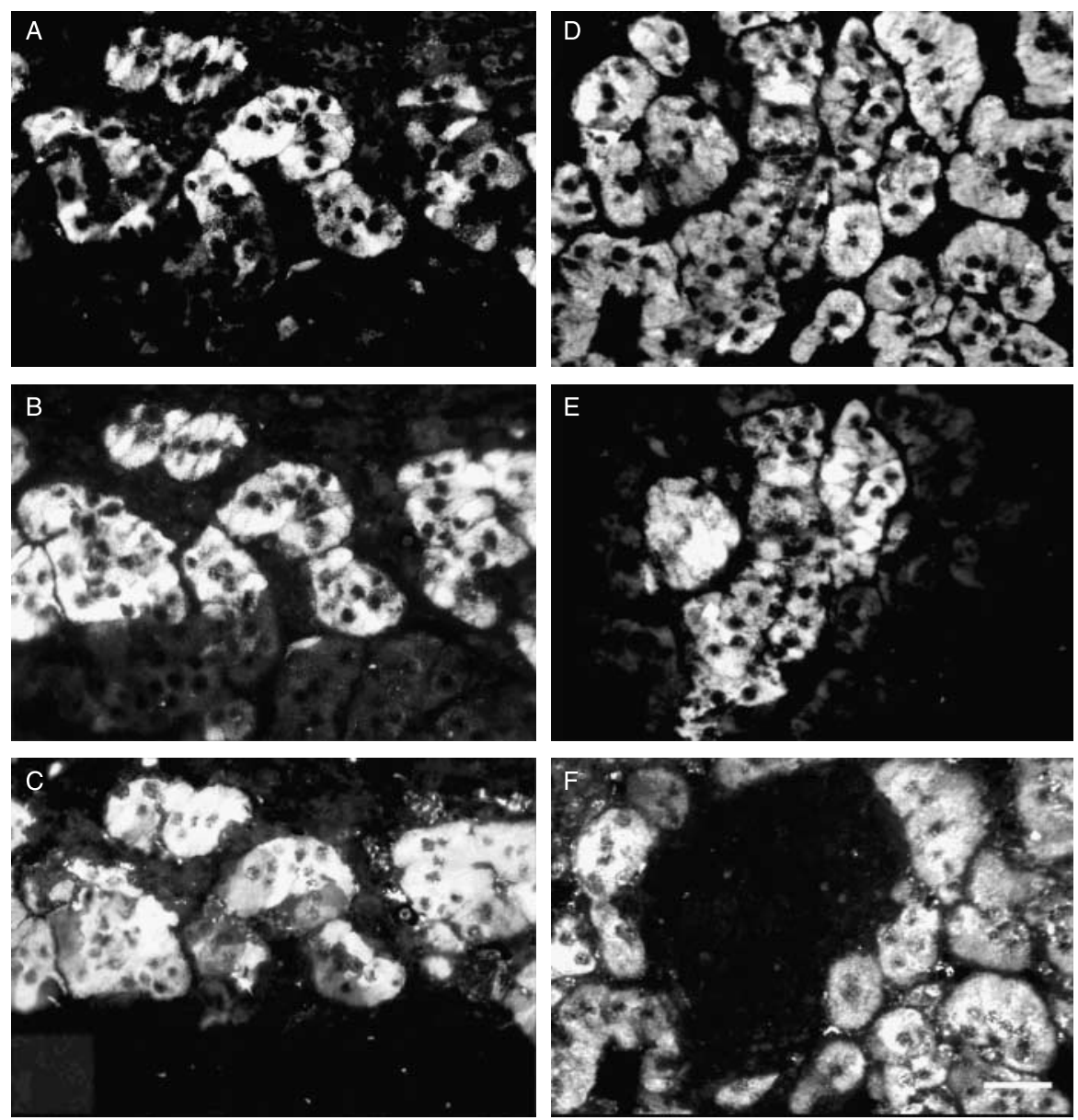

Figure 3 Differential distribution in adrenaline versus nor-adrenaline cells. (B) TLQP peptides were shown in almost all cells immunostained for the adrenaline-synthesizing enzyme phenylethanolamine-N-methyl transferase (PNMT; C), many of which also labelled for the (A) VGF C-terminus. Conversely, in all three species studied, (E) HVLL immunoreactivity was confined to medullary cells reactive for dopamine $\beta$-hydroxylase $(\mathrm{DBH}$; D) but not for PNMT $(\mathrm{F})$, hence identified as noradrenaline cells. Swine adrenal, triple immunofluorescence (A-C, D-F); scale bars, $50 \mathrm{~m}(\mathrm{~A}-\mathrm{F})$.

seen in a broader band around $0 \cdot 8-1 \cdot 3 \mathrm{kDa}$ (Fig. 4C). The high MW peak shown with the HVLL assay is likely to represent intact VGF, in keeping with the degree of crossreactivity of VGF C-terminus peptides in such assay (Table 2). Hence, only small heterogeneous fragments would account for adrenal HVLL peptide immunoreactivity (Fig. 4D). In rat adrenal extracts, the TLQP and C-terminus peptides showed a profile comparable with that seen in swine and bovine with similarly migrating peaks, while the HVLL and PGH peptides were not tested in view of their low concentrations.

When adrenal extracts from minimum stress and acute stress swine were compared in parallel assays, clear-cut differences were revealed (Fig. 5). Adrenal extracts from the acute stress group were closely comparable with previous samples of swine adrenals taken at random after butchery from a local abattoir (no significant difference in either VGF C-terminus, TLQP or PGH peptides, while HVLL peptides were not assessed). When the minimum stress animals were set as the reference control group, a striking fivefold increase was revealed for VGF C-terminus peptides, with an about threefold increase in TLQP peptides and no significant change for $\mathrm{PGH}$ peptides (Fig. 5, left panel). A similar pattern was seen in acutely stressed rats (Fig. 5, middle panel), with a clear-cut increase in TLQP peptides, which increased further after a 30-min recovery period (Fig. 5, right panel). Upon gel chromatography, no distinct changes were revealed in the relative proportions of the various molecular forms of TLQP (all species) and C-terminus VGF peptides (bovine and swine), across the minimum stress and stressed animals (not shown).

\section{Discussion}

On the basis of the present study, VGF and derived peptides are well represented in the adrenal gland of several mammalian 
Table 3 VGF peptide concentrations (pmol/g wet tissue weight) in adrenal extracts. Values are mean \pm s.E.M.

\begin{tabular}{|c|c|c|c|c|}
\hline & Bovine random $^{a}$ & Swine random ${ }^{a}$ & Rat random $^{\mathrm{a}}$ & Rat minimum stress ${ }^{b}$ \\
\hline TLQP peptides ${ }^{\mathrm{d}}$ & $160 \pm 40$ & $358 \pm 40$ & $172 \pm 48$ & $97 \pm 19$ \\
\hline HVLL peptides $^{f}$ & $<45$ & $<30$ & $<\overline{10}$ & $<10^{-}$ \\
\hline
\end{tabular}

$n=7$ swine, 15 bovine, 10 and 10 rats respectively. $* P<0 \cdot 005$, other differences between two rat groups were not significant.

${ }^{a}$ Random samples from abattoir line or sequentially killed rats.

${ }^{\mathrm{b}}$ All rats from each cage killed at the same time (see text).

${ }^{\mathrm{C}}$ Human and rat C-terminus assays, for swine/bovine, and rat tissues respectively.

${ }^{\mathrm{d} C}$ Calculated as rat TLQP-21 equivalent for all three species.

${ }^{\mathrm{e}}$ Human TPGH and rat APGH assays, for swine/bovine and rat tissues respectively.

${ }^{f}$ Below detection in $20-30 \%$ of samples studied.

species. VGF has not been sequenced in swine and partly in bovine (accession No. XP_875466.2), bovine C-terminus and $\mathrm{PGH}$ peptide regions being almost identical to human VGF, while the TLQP peptide domain remains to be determined. The parallel distribution profiles we found in the three species studied argue for a largely conserved primary structure, relevant to immunohistochemical findings and to intra-species comparative results obtained by immunochemistry. Conversely, numerical values of tissue peptide concentrations measured ought to be considered with caution, pending sequencing of the relevant peptides, hence use of proper standards. In this respect, we used rat TLQP-21 as reference standard for all three species. In rat adrenal, we measured relatively low concentrations of VGF C-terminus peptides compared with those found in mouse brain (100$1500 \mathrm{pmol} / \mathrm{g}$, depending on areas; Chakraborty et al. 2006). Pending further characterization of the degree of reactivity of all molecular forms involved, one ought to note that our antibodies were strictly selective for an intact C-terminus, removal of the last three amino acids or substitution of one, resulting in complete loss of reactivity. The AQEE peptide assay used by Chakraborty et al. (2006) was selective for an extended, at least 19 amino acid region upstream of the C-terminus, and the molecular forms involved were not determined.

A major finding of the present study is that different VGF peptide profiles were revealed for adrenaline versus noradrenaline medullary cells. Altogether, our findings argue for a variety of VGF peptides, derived from extended regions within VGF, being produced and probably released by the former cells. These would probably include a 62 amino acid form running from the TLQP region to the VGF C-terminus (similar to the VGF10, or TLQP-62 peptide found in rat brain; Trani et al. 2002), as well as shorter TLQP and C-terminal peptides respectively. The low amounts of small HVLL peptides we found, confined to nor-adrenaline cells, may represent degradation products derived from the C-terminal portion of VGF. Nonetheless, the abundance of PGH peptides throughout swine and bovine adrenaline as well as nor-adrenaline cells (and in fewer corresponding cells in the rat) suggests that such peptides may have a role in the secretory repertoire of both cell types. PGH peptides share a common sequence and apparent abundance in the adrenal between at least bovine and human, both species also showing intermediate-high MW adrenal PGH peptides encompassing more or less extended domains towards the VGF N-terminus (Rindi et al. 2007).

A second major point is the rapid, differential inducibility of VGF peptides in adrenal medullary cells, with a major several fold increase in tissue concentrations of some such peptides, while others showed little change. As mentioned, a clear-cut induction of VGF mRNA was revealed in rat after the administration of reserpine, probably via activation of sympathetic nerves, together with a parallel rise in various secretogranins/chromogranins, as well as neuropeptide Y (Laslop et al. 1994). While the latter increase in VGF mRNA lasted throughout the study (days 1-5), the far shorter time frame of the changes we observed points out a very rapid capacity for response, well before novel mRNA synthesis is likely to be involved. Hence, a combination of increased VGF precursor biosynthesis from existing mRNA, as well as VGF precursor processing is likely to have occurred in our experimental set-up. While the above, longer term changes were considered to increase the secretory content of secretory vesicles under prolonged stimulation (Laslop et al. 1994), the rapid changes of certain VGF peptides could be involved in a promptly evoked short-term response. Further to the acutely stressed groups, our random sacrifice rats also showed a tendency to increase in TLQP peptides, the high variability observed being possibly related to a highly varied amount of stress, since animals from each cage were randomly killed in sequence. The significance of such higher TLQP and VGF C-terminus peptides and their involvement in local and/ or systemic adaptive changes is presently unknown. Investigations focussed onto VGF peptide release into the bloodstream are warranted, aimed at addressing the possible role of such peptides as circulating mediators or hormones, as well as potential biomarkers in various stress conditions. As to the central nervous system counterpart, a significant increase in C-terminus-related VGF peptides was shown in mouse females, but not males, upon exposure to cold or to 

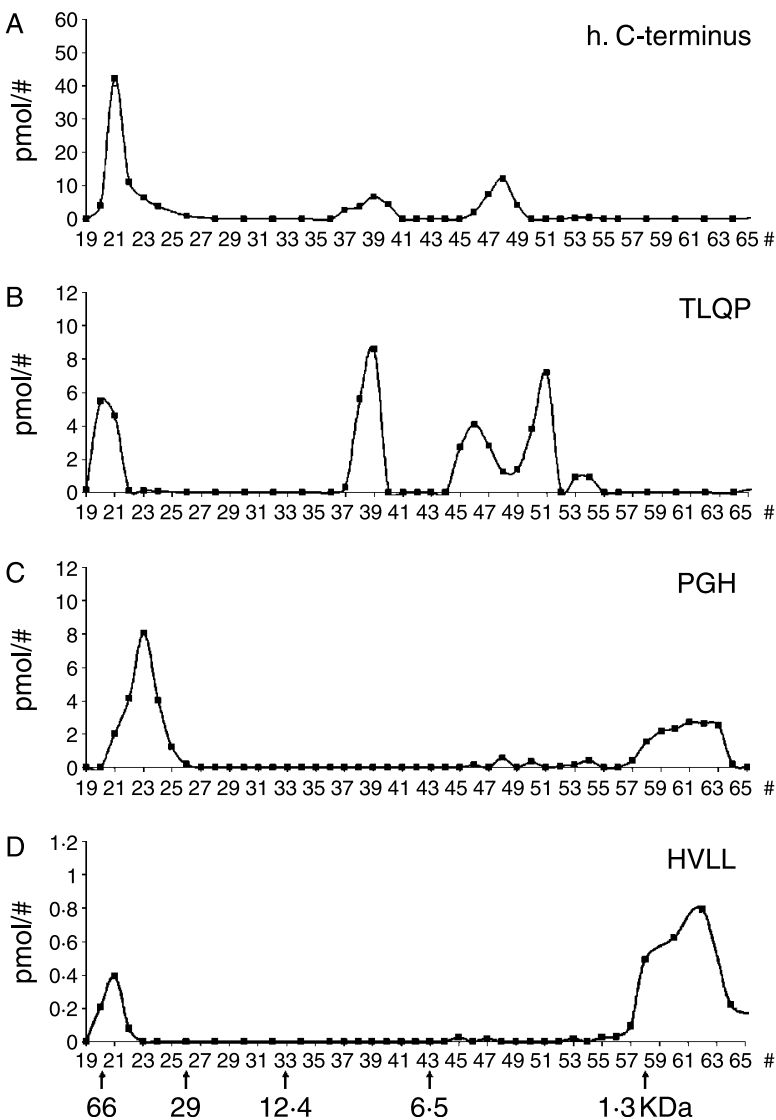

Figure 4 Chromatographic profile of VGF peptides. Several antisera (A, B and D) showed a high MW peak compatible with intact VGF. Additional peptides migrated at $\sim 7.5$ and $\sim 3.5 \mathrm{kDa}$, VGF

C-terminus peptides at $\sim 7.5 \mathrm{kDa}$ and in the $\sim 5-2.5 \mathrm{kDa}$ region for TLQP peptides, or as low MW forms $(1 \cdot 3-0 \cdot 8 \mathrm{kDa}, \mathrm{PGH}$ and HVLL peptides). The rat PGH peptide antiserum showed no VGF-like forms, in keeping with its very low reactivity with C-terminally extended $\mathrm{PGH}$ peptides. Conversely, the same antiserum revealed an intermediate-high MW form ( 40-50 kDa; C). 'h C-terminus', human VGF C-terminus peptides; swine adrenal extracts.

a high carbohydrate, high-fat diet (Chakraborty et al. 2006). Although pituitary VGF peptides were not studied here in connection with stress, none were revealed in ACTH cells in either sheep or rat, which had been butchered or killed, as our respective random sacrifice swine/bovine (Brancia et al. 2005) or rats (Ferri et al. 1995). Further investigations of different stress models, as well as addressing a wider range/s of VGF peptides will need to be carried out, focussing on both the hypothalamus-pituitary-adrenal cortex axis, as well as the sympathoadrenal system.

The comparatively high amounts of TLQP peptides we found are of special interest, since the increase in energy consumption induced by TLQP-21 (Bartolomucci et al. 2006) was at least partly mediated via increased circulating levels of adrenaline. Although peripheral administration of TLQP-21 was apparently devoid of effects, at least in the

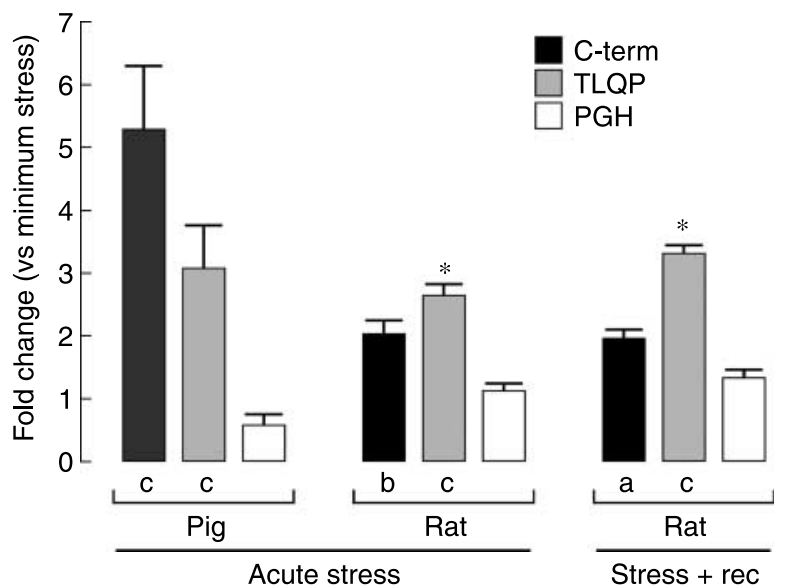

Figure 5 Changes in acutely stressed swine and rats versus minimum stress. After being stabulated at a local abattoir for over 3 days, minimum stress swine were butchered first in the day (1-5 min waiting on a clean abattoir line), while acute stress ones waited in line for 25-30 min before being stunned (with electricity) and ejugulated. Rats were subjected to acute stress (5 min swimming) or the same stress followed by a 30-min recovery (stress + rec). A striking increase in tissue TLQP and/or VGF C-terminus peptides was shown in both swine and rats, rat TLQP peptides further increasing after the 30 min recovery period (results expressed as fold change compared with minimum stress animals; means \pm s.E.M.; ' $\mathrm{a}$ ', $P<0.01$; ' $\mathrm{b}$ ', $P<0.001$; ' $\mathrm{C}^{\prime}, P<0 \cdot 0001$ compared with relevant minimum stress group; ${ }^{*} P<0 \cdot 025$ between two groups indicated; other differences not significant).

Siberian Hamster (Jethwa et al. 2007), the comparatively high amounts and molecular heterogeneity of TLQP peptides we found in the adrenal of three mammalian species should not be overlooked. Interestingly, yet to be characterized VGF-immunoreactive peptides were shown in sympathetic neurons (Ferri et al. 1998), too, hence it is not unlikely that TLQP-like peptide/s may be present in further endocrine and neuronal systems. A peripheral regulatory role might thus be considered, as recently shown for neuropeptide $Y$, which is found in both adrenal medulla and sympathetic efferent nerves, and may mediate stress-induced obesity and aspects related to the metabolic syndrome via peripheral mechanisms (Kuo et al. 2007).

As to the multiplicity of VGF-derived peptides, it is becoming clear that various heterogeneous and possibly organ- and/or cell type-selective profiles of VGF peptides may exist, as we have shown so far for the sheep pituitary (Brancia et al. 2005), as well as the swine and bovine pancreatic islets (Cocco et al. 2007). Along a similar line, a striking degranulation of VGF peptides, including PGH peptides, was shown in rat female pituitary gonadotrophes on the morning following oestrus (Ferri et al. 1995). In turn, such heterogeneity of VGF peptides implies a complex pattern of cell-specific processing of the VGF precursor, which has been only partly clarified. The VGF10 form found in rat brain could be generated by either of the 
neuroendocrine-specific prohormone convertases $\mathrm{PC} 1 / 3$ or PC2 (Trani et al. 2002), and probably corresponds to the $\sim 7.5 \mathrm{kDa}$ VGF C-terminus immunoreactive form we found. Conversely, we could not reveal any form corresponding to a larger peptide, named VGF20 and found in rat brain, which was preferentially produced by the PC1/3 convertase (Trani et al. 2002). Interestingly, other hormones involved in feeding and metabolic regulatory mechanisms undergo tissue-specific processing, such as pro-glucagon, which can be cleaved by the PC1 enzyme in intestinal $\mathrm{L}$ cells to form glicentin, oxyntomodulin, GLP-1 and GLP-2, or is processed by PC2 in pancreatic $\alpha$ cells to yield glucagon and miniglucagon, with the relevant diversity of biological actions (Bataille 2007).

Finally, the possibility of intracellular roles for at least some VGF-derived peptides should be mentioned, as has been shown for various chromogranins and their multiple products, involved in a long list of both intra- and extracellular regulatory mechanisms (Zhang et al. 2006).

In conclusion, VGF peptides appear to be widely expressed, differentially processed, as well as rapidly, selectively induced in adrenal medullary cells. Their processing from the single VGF precursor may flexibly provide several peptide hormones and/or intracellular regulators of varied biological activity relevant to adaptive responses.

\section{Acknowledgements}

G Boi, F Incollu, G Steri, M Regali, G Desogus, Coalbe and Valriso Companies, M C Mostallino at the CNR Institute of Neuroscience, Cagliari are thanked for tissue samples, and G J Dockray for advise and discussion at the early stages of this work. Partly supported by Research Grants from MIUR FIRB (RBNE013XSJ_002 and RBNE01JKLF_002), and Ministry of Health, Italy. F D and C C carried out immunocytochemistry; F D, B N, C B Elisa experiments; M C and G F rat experiments; G L F initiated and supervised the study and produced VGF antisera with P N; F D, C C, G L $\mathrm{F}$ wrote the paper. The authors declare that there is no conflict of interest that would prejudice the impartiality of this scientific work.

\section{References}

Bartolomucci A, La Corte G, Possenti R, Locatelli V, Rigamonti AE, Torsello A, Bresciani E, Rizzi R, Pavone F et al. 2006 TLQP-21, a novel VGFderived peptide, increases energy expenditure and prevents the early phase of diet-induced obesity. PNAS 103 14584-14589.

Bataille D 2007 Pro-protein convertases intermediary metabolism: islet hormones, brain/gut hormones and integrated physiology. Journal of Molecular Medicine 85 673-684.

Brancia C, Nicolussi P, Cappai P, La Corte G, Possenti R \& Ferri GL 2005 Differential expression and seasonal modulation of VGF peptides in sheep pituitary. Journal of Endocrinology 186 97-107.
Canu N, Possenti R, Rinaldi AM, Trani E \& Levi A 1997 Molecular cloning and characterization of the human VGF promoter region. Journal of Neural Transmission 68 1390-1399.

Chakraborty TR, Tkalych O, Nanno D, Garcia AL, Devi LA \& Salton SR 2006 Quantification of VGF- and pro-SAAS-derived peptides in endocrine tissues and the brain, and their regulation by diet and cold stress. Brain Research 1089 21-32.

Cocco C, Melis GV \& Ferri G-L 2003 Embedding media for cryomicrotomy: an applicative reappraisal. Applied Immunohistochemistry and Molecular Morphology 11 274-280.

Cocco C, Brancia C, Pirisi I, D’Amato F, Noli B, Possenti R \& Ferri GL 2007 VGF metabolic-related gene: distribution of its derived peptides in mammalian pancreatic islets. Journal of Histochemistry and Cytochemistry 55 619-628.

Ferri G-L, Levi A \& Possenti R 1992 A novel neuroendocrine gene product: selective VGF8a gene expression and immuno-localisation of the vgf protein in endocrine and neuronal populations. Brain Research. Molecular Brain Research 13 139-143.

Ferri GL, Gaudio RM, Cossu M, Rinaldi AM, Polak JM, Berger P \& Possenti R 1995 The 'VGF' protein in rat adenohypophysis: sex differences and changes during the estrous cycle and after gonadectomy. Endocrinology 136 2244-2251.

Ferri G-L, Albers KM \& Possenti R 1998 Changes in the neurotrophininducible protein 'VGF' in mice hyperexpressing NGF. Social Neuroscience Abstracts 24630.

Hahm S, Mizuno TM, Wu TI, Wisor JP, Priest CA, Kozoc CA, Boozer CN, Peng B, Mcevoy RC, Good P et al. 1999 Targeted deletion of the gene indicates that the encoded secretory peptide precursor plays a novel role in the regulation of energy balance. Neuron 23 537-548.

Hahm S, Fekete C, Mizuno TM, Windsor J, Yan H, Boozer CN, Lee C, Elmquist JK, Lechan RM, Mobbs CV et al. 2002 VGF is required for obesity induced by diet, gold thioglucose treatment, and Agouti and is differentially regulated in pro-opiomelanocortin- and neuropeptide Y-containing arcuate neurons in response to fasting. Journal of Neuroscience 22 6929-6938.

Jethwa PH, Warner A, Nilaweera KN, Brameld JM, Keyte JW, Carter WG, Bolton N, Bruggraber M, Morgan PJ, Barrett P \& Ebling FJ 2007 VGFderived peptide, TLQP-21, regulates food intake and body weight in Siberian hamsters. Endocrinology 148 4044-4055.

Kuo LE, Kitlinska JB, Tilan JU, Li L, Baker SB, Johnson MD, Lee EW, Burnett MS, Fricke ST, Kvetnansky R et al. 2007 Neuropeptide Y acts directly in the periphery on fat tissue and mediates stress-induced obesity and metabolic syndrome. Nature Medicine 13 803-811.

Laslop A, Mahata SK, Wolkersdorfer M, Mahata M, Srivastava M, Seidah NG, Fischer-Colbrie R \& Winkler H 1994 Large dense-core vesicles in rat adrenal after reserpine: levels of mRNAs of soluble and membrane-bound constituents in chromaffin and ganglion cells indicate a biosynthesis of vesicles with higher secretory quanta. Journal of Neurochemistry 62 2448-2456.

Levi A, Eldridge JD \& Paterson BM 1985 Molecular cloning of a gene sequence regulated by nerve growth factor. Science 229 393-395.

Levi A, Ferri GL, Watson E, Possenti R \& Salton SRJ 2004 Processing, distribution, and function of VGF, a neuronal and endocrine peptide precursor. Cellular and Molecular Neurobiology 24 517-533.

Liu J-W, Andrews PC, Mershon JL, Yan C, Allen DL \& Ben-Jonathan N 1994 Peptide V: a VGF-derived neuropeptide purified from bovine posterior pituitary. Endocrinology 135 2742-2748.

Possenti R, Eldridge JD, Paterson BM, Grasso A \& Levi A 1989 A protein induced by NGF in PC12 cells is stored in secretory vesicles and released through the regulated pathway. EMBO Journal 8 2217-2223.

Possenti R, Rinaldi AM, Ferri G-L, Bordoni P, Trani E \& Levi A 1999 Expression, processing, and secretion of the neuroendocrine VGF peptides by INS-1 cells. Endocrinology 140 3727-3735.

Rindi G, Licini L, Necchi V, Bottarelli L, Campanini N, Azzoni C, Favret M, Giordano G, D'Amato F, Brancia C, Solcia E \& Ferri G-L 2007 Peptide products of the neurotrophin-inducible gene vgf are produced in human neuroendocrine cells from early development, and increase in hyperplasia and neoplasia. Journal of Clinical Endocrinology and Metabolism 92 2811-2815. 
Salton SR, Fischberg DJ \& Dong KW 1991 Structure of the gene encoding VGF, a nervous system-specific mRNA that is rapidly and selectively induced by nerve growth factor in PC12 cells. Molecular Cell Biology 11 2335-2349.

Salton SRJ, Ferri GL, Hahm S, Snyder SE, Wilson AJ, Possenti R \& Levi A 2000 VGF: a novel role for this neuronal and neuroendocrine polypeptide in the regulation of energy balance. Frontiers in Neuroendocrinology 21 199-219.

Trani E, Rinaldi AM, Canu N, Ciotti MT, Ferri G-L, Levi A \& Possenti R 1995 Tissue-specific processing of neuroendocrine protein VGF. Journal of Neurochemistry 65 2441-2449.

Trani E, Giorni A, Canu N, Amadoro G, Rinaldi AM, Halban PA, Ferri G-L, Possenti R, Schiniń ME \& Levi A 2002 Isolation and characterization of VGF peptides in rat brain, role of PC1/3 and PC2 in the maturation of VGF precursor. Journal of Neurochemistry $\mathbf{8 1} 565574$.
Zhang K, Rao F, Wen G, Salem RM, Vaingankar S, Mahata M, Mahapatra NR, Lillie EO, Cadman PE, Friese RS et al. 2006 Catecholamine storage vesicles and the metabolic syndrome: the role of the chromogranin A fragment pancreastatin. Diabetes, Obesity and Metabolism 8 621-633.

Received in final form 3 February 2008

Accepted 13 February 2008

Made available online as an Accepted Preprint

13 February 2008 